\title{
CLINICAL STUDY OF PAEDIATRIC DERMATOSES IN OSMANIA GENERAL HOSPITAL, HYDERABAD, TELANGANA DURING THE PERIOD DECEMBER 2015 TO JUNE 2016
}

\author{
N. Sudheer ${ }^{1}$, A. Venkat Krishna², T. Yaswanth ${ }^{3}$
}

${ }^{1}$ Assistant Professor, Department of DVL, Osmania Medical College/Hospital.

${ }^{2}$ Associate Professor, Department of DVL, Osmania Medical College/Hospital.

3Junior Resident, Department of DVL, Osmania Medical College/Hospital.

\section{ABSTRACT}

\section{BACKGROUND}

Paediatric dermatoses constitute various skin diseases (both infective and non-infective) effecting the paediatric age groups. Infective dermatoses being bacterial, viral and fungal infections. Non-infective dermatoses being atopic dermatitis, seborrheic dermatitis, vesiculobullous diseases, keratinisation disorders, papulosquamous disorders, pigmentary disorders, etc. The purpose of the study was to see dermatoses commonly affecting paediatric age groups (0 to 14 years) in Osmania General Hospital over a period of six months (December 2015 to June 2016).

\section{METHODS}

This study was conducted in DVL Department at Osmania General Hospital, Hyderabad. All children below 14 years attending the dermatology outpatient department with any form of dermatoses between the period of December 2015 to June 2016 were enrolled in the study. The diagnosis was made by dermatologist based on detailed history, clinical features and appropriate investigations such as $\mathrm{KOH}$ examination, Tzanck test, gram stained smear, haematological and biochemical investigations, X-ray, VDRL, skin biopsies, etc. The diseases were tabulated based on the aetiology and the results were analysed.

\section{RESULTS}

The most common dermatoses encountered were infections and infestations, which were seen in $52.4 \%$ of the study population. Dermatitis and eczema constituted about 29.2\%, Papulosquamous dermatoses were about 18.82\%, Nutritional dermatoses was about 3.8\%, Urticaria and allergic disorders were about $2.4 \%$, Drug reactions were about $1.6 \%$, Genetic disorders were $1.5 \%$, Seasonal disorders were about $1.2 \%$, Pigmentary disorders were about $2.5 \%$, Keratinisation disorders constituted $0.4 \%$ and bullous dermatoses constituted about $0.4 \%$ in our study; $4 \%$ of the patients had more than one dermatoses.

\section{CONCLUSIONS}

Scabies was the most common infection in our study and comprised $63.74 \%$ of infections and infestations. Our study brings into light the unique features of tropical dermatology such as high frequency of dermatoses like Infections and Infestations, Eczema and Dermatitis, Environment Associated Disorders like papular urticaria and miliaria. The occurrence of rare genetic and other dermatoses is remarkable in our institute as our hospital is a tertiary hospital located in Hyderabad City.

\section{KEYWORDS}

Paediatric Dermatoses, Tropical Dermatology, Infections, Eczemas.

HOW TO CITE THIS ARTICLE: Sudheer N, Krishna AV, Yaswanth T. Clinical study of paediatric dermatoses in Osmania General Hospital, Hyderabad, Telangana during the period December 2015 to June 2016. J. Evolution Med. Dent. Sci. 2016;5(73):53995403, DOI: $10.14260 /$ jemds/2016/1225

\section{INTRODUCTION}

Paediatric dermatoses constitute various skin diseases (both infective and non-infective) effecting the paediatric age groups. ${ }^{1}$ Paediatric Dermatoses account for considerable member of patients attending outpatient clinics.

The aim of the clinical study on paediatric dermatoses is to study the incidence and prevalence of various skin dermatoses affecting paediatric age group. Locally some of the dermatoses are more common in the children on account of various factors. ${ }^{1 \& 2}$ Though paediatric dermatoses do not cause mortality, they cause a lot of morbidity.

Financial or Other, Competing Interest: None.

Submission 02-08-2016, Peer Review 30-08-2016,

Acceptance 06-09-2016, Published 12-09-2016.

Corresponding Author:

Dr. N. Sudheer,

H. No: 2-2-24/bl/15/6,

DD Colony, Bagh Amberpet, Hyderabad-13.

E-mail: neelamsudheer8@gmail.com

DOI: $10.14260 /$ jemds/2016/1225
Lack of awareness, illiteracy, bad personal hygiene, climatic factors, overcrowding contribute to the increased incidence of certain infections. ${ }^{1 \& 3}$ Certain dermatoses are seasonal like miliaria, periporitis, xerosis, polymorphic light eruption. Some dermatoses are genetic. Eg: Vesiculobullous diseases, keratinisation disorders.

Some disease like scabies and pediculosis are common in people who lack personal hygiene and where there is overcrowding and poverty. ${ }^{3}$ Scabies and pediculosis can infect many children at the same time in hostels and all the family members if proper precautions are not taken.

Nutritional deficiency disorders can affect children causing phrynoderma, pigmentation (Hyper and hypo), Cheilitis, hair and nail changes.

Atopic dermatitis and seborrheic dermatitis can effect infants and children, pre-disposing the children to various other infections and skin problems. Early detection and management of paediatric dermatoses at peripheral centres helps us to combat the problems and reduce the morbidity, as they are the first people to see the patients. 
As per the paediatricians and hospital records, patients in the age group 0 to 14 years were taken into the study. There are certain problems which are exclusive to children on account of their age, skin condition and immunological status. ${ }^{4}$ For e.g. Atopic dermatitis and seborrheic dermatitis involve infants and the condition improves with the age of the patients. Similarly certain bullous disorders effect children in the early age. Scabies can effect infants causing vesicular lesions on the hands and feet. Various studies have been done all over the world and India to see the common dermatoses affecting children.(1)

We undertook the study to determine the pattern of common dermatoses presenting to a Tertiary Centre, Osmania General Hospital, Hyderabad.

\section{CLASSIFICATION}

Distribution as per aetiology of various dermatoses in children.

- Infections and infestations.

- Dermatitis and eczema.

- Vesiculobullous disorders.

- Papulosquamous disorders.

- Urticaria and allergic dermatitis.

- Pigmentary disorders.

- Congenital disorders.

- Keratinisation disorders.

- Nutritional dermatoses.

- Photosensitive dermatoses.

- Drug reactions.

- Seasonal Dermatoses.

\section{AIMS AND OBJECTIVES}

As there is no study done on incidence and prevalence of paediatric dermatoses in Telangana State, we have taken up the study to see the pattern of dermatoses in children aged less than 14 years attending the DVL outpatient department at Osmania General Hospital, Hyderabad, and treat the problem at an early stage so as to reduce the morbidity and incidence of the diseases.

Children less than 14 years presenting to us between December 2015 and June 2016 were studied. A total of 500 children (277 males, 223 females) with various dermatoses were recorded randomly.

The cross-sectional study was carried out to see the percentage of occurrence of various dermatoses in Hyderabad city and compare the pattern of dermatoses with other areas in India and treat the problem at an early stage, so as to reduce the morbidity and incidence of the diseases.

\section{MATERIALS AND METHODS}

This study was conducted in DVL Department at Osmania General Hospital, Hyderabad. The climate of this region is typically like that of a tropical area with high temperature and humidity.

All children below 14 years attending the dermatology outpatient department with any dermatoses between the period of December 2015 to June 2016 were enrolled in the study. The diagnosis was made by dermatologist based on detailed history, clinical features and appropriate investigations such as $\mathrm{KOH}$ examination, Tzanck test, gram stained smear, haematological and biochemical investigations, X-ray, VDRL, skin biopsies.

The diseases were tabulated based on the aetiology and the results were analysed.

\section{OBSERVATION AND RESULTS}

During the study period of 6 months, i.e. from December 2015 to June 2016; 5000 new cases attended our outpatient department. A total of 500 children with various dermatoses were seen during the study period. Among the children 22 of them had more than one dermatoses. The age and sex distribution of the study is shown in Table I.

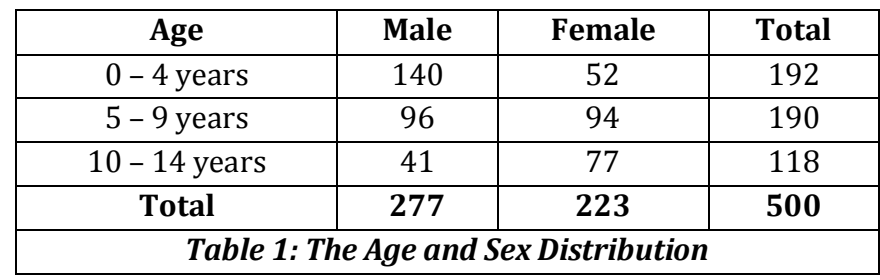

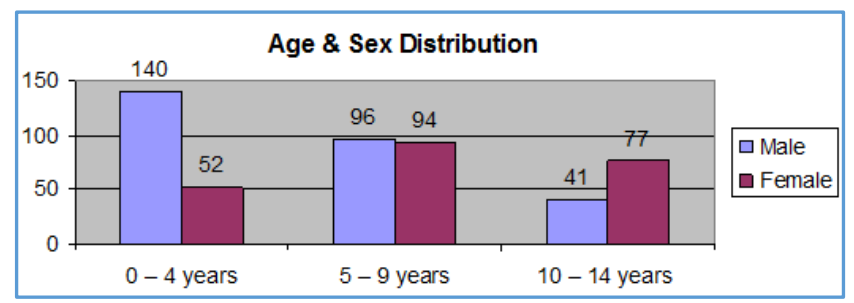

The dermatoses included in the study are classified as shown in Table 2.

\begin{tabular}{|c|c|c|c|}
\hline $\begin{array}{c}\text { Sl. } \\
\text { No. }\end{array}$ & Dermatosis & $\begin{array}{c}\text { No. of } \\
\text { Cases }\end{array}$ & \% \\
\hline 1. & Infections and infestations & 262 & 52.4 \\
\hline 2. & Dermatitis and eczema & 146 & 29.2 \\
\hline 3. & Bullous dermatosis & 2 & 0.4 \\
\hline 4. & Papulosquamous dermatosis & 17 & 18.82 \\
\hline 5. & Urticaria and Allergic & 12 & 2.4 \\
\hline 6. & dermatitis & 12 & 2.4 \\
\hline 7. & Genentary dermatosis disorders & 7 & 1.4 \\
\hline 8. & Keratinisation disorders & 2 & 0.4 \\
\hline 9. & Nutritional dermatosis & 19 & 3.8 \\
\hline 10. & Photosensitive dermatosis & 8 & 1.6 \\
\hline 11. & Seasonal dermatosis & 6 & 1.2 \\
\hline 12. & Drug reactions & 8 & 1.6 \\
\hline \multicolumn{4}{|c|}{ Total } \\
\hline \multicolumn{4}{|c|}{ Table 2: Distribution of Aetiology of } \\
\hline \multicolumn{4}{|c|}{ Various Dermatosis in Children } \\
\hline
\end{tabular}




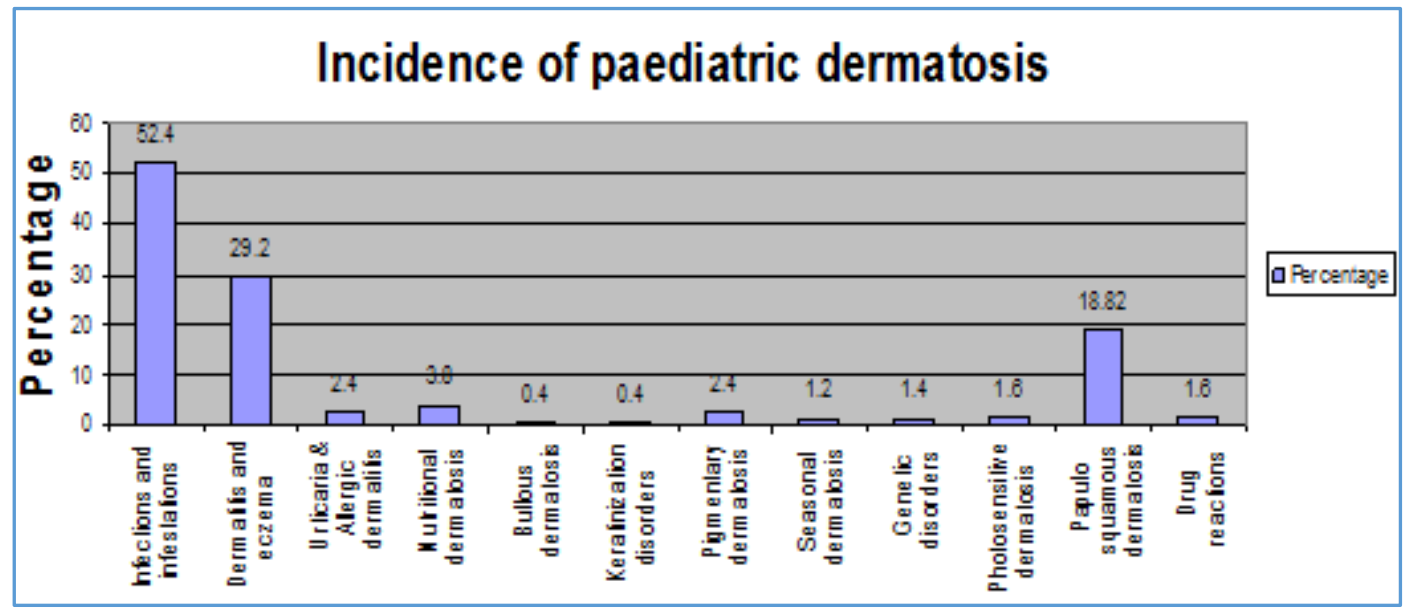

The various dermatoses included in the classification as per aetiology are:

\section{INFECTIONS AND INFESTATIONS \\ Bacterial}

Impetigo, secondary pyodermas, ecthyma, folliculitis, furuncles, cellulitis, erysipelas.

\section{Fungal Infections}

Tinea capitis, Tinea corporis, Candidiasis, Intertrigo, pityriasis versicolor.

\section{Viral Infections}

Verruca vulgaris, molluscum contagiosum, herpes simplex, herpes zoster.

\section{Infestations}

Scabies, pediculosis

\section{Eczema and Dermatitis}

Atopic dermatitis, seborrheic dermatitis, cradle cap, discoid eczema, papular urticaria, prurigo nodularis. Juvenile plantar dermatitis.

\section{Urticaria and Allergic Contact Dermatitis}

Urticaria and allergic contact dermatitis.

\section{Nutritional Dermatoses}

Phrynoderma, pellagra, glossitis, cheilitis, hyper and hypopigmentation of skin.

\section{Bullous Disorders}

- Epidermal bullosa simplex.

- Epidermal bullosa dystrophica.

\section{Keratinisation Disorders}

Ichthyosis vulgaris, lamellar ichthyosis.

\section{Pigmentary Dermatoses}

Vitiligo.

\section{Seasonal Dermatosis}

Miliaria, periporitis, xerosis.

\section{Congenital Disorders}

- Haemangioma.
- Lymphangioma Circumscriptum.

- Linear epidermal naevus.

- Melanocytic naevus.

- Aplasia cutis.

Photosensitive Dermatosis

Polymorphic light eruption.

\section{Papulosquamous Disorders}

Psoriasis, lichen planus, lichen nitidus.

\section{Drug Reactions}

Drug rash, fixed drug eruption, erythema multiforme, StevenJohnson syndrome.

The pattern of various infections and infestations are shown in Table 3.

\begin{tabular}{|c|c|c|c|}
\hline Sl. No. & Pattern & No. of Cases & Percentage \\
\hline \multicolumn{5}{|c|}{ Infections } \\
\hline 1. & Pyodermas & 12 & 21.05 \\
\hline 2. & Impetigo contagiosa & 10 & 17.54 \\
\hline 3. & Bullous impetigo & 12 & 21.05 \\
\hline 4. & Furunculosis & 14 & 24.50 \\
\hline 5. & Folliculitis & 9 & 15.78 \\
\hline \multicolumn{4}{|c|}{ Total Infestations } \\
\hline \multicolumn{5}{|c|}{ Fungal Infections } \\
\hline 1. & Scabies & 160 & 95.80 \\
\hline 2. & Pediculosis & 7 & 4.19 \\
\hline \multicolumn{5}{|c|}{ Total } & 10 & 38.48 \\
\hline 1. & Tinea capitis & 11 & 42.31 \\
\hline 2. & Tinea corporis & 5 & 19.23 \\
\hline 3. & Candidiasis & $\mathbf{1 6 7}$ & \\
\hline \multicolumn{4}{|c|}{ Total } \\
\hline
\end{tabular}

\begin{tabular}{|c|c|c|c|}
\hline \multicolumn{4}{|c|}{ Viral Infections } \\
\hline 1. & Warts & 4 & 33.30 \\
\hline 2. & Molluscum contagiosum & 1 & 8.30 \\
\hline 3. & Varicella & 2 & 16.60 \\
\hline 4. & Herpes simplex & 5 & 41.60 \\
\hline & Total & 12 & \\
\hline
\end{tabular}




\section{Pattern of Infections \& Infestations}

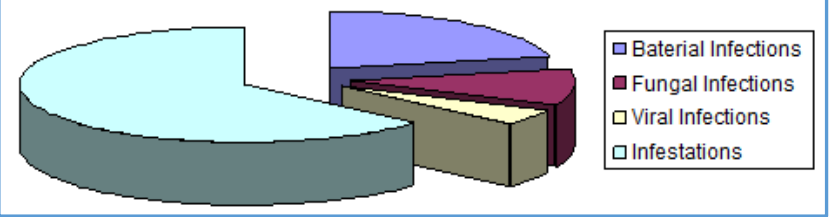

As per our observation, infections and infestations were the most common dermatoses followed by dermatitis and eczema which was followed by papulosquamous disorders.

Routine biochemical, haematological, pathological investigations were normal in most of the patient. Few patients with dermatophyte infections showed septate hyphae in $\mathrm{KOH}$ mount, some of the patients with Atopic dermatitis showed raised serum IgE levels.

\section{DISCUSSION}

Dermatology problems constitute at least $30 \%$ of all outpatient's visit to a Paediatrician and $30 \%$ of all visits to a dermatologists involve children. ${ }^{1 \& 2}$ The prevalence of skin diseases amongst children in various parts of India ranged from $8.7 \%$ to $35 \%$ in school based survey. ${ }^{3}$ Schools from rural areas showed relatively high prevalence of skin diseases.

The pattern of skin diseases in children is very much influenced by climate, external environment, dietary habits and socio-economic status. $(4,5)$

The present study brings into focus the pattern of paediatric dermatoses encountered in Osmania General Hospital, Hyderabad.

The most common dermatoses encountered were infections and infestations, which were seen in $52.4 \%$ of the study population.

Negi et $\mathrm{al}^{6}$ in their study found infections and infestations contributed to $50 \%$ of the cases in Garhwal region of Uttar Pradesh.

Various other authors have reported them occurring in the range of $35.6 \%$ to $85.2 \% .(6,7,8,9)$

In all these studies whether institution based or community based infections and infestations were the main group of dermatosis.

The higher frequency of infections and infestations in our study could possibly be due to large rural population attending our hospital belonging to low socio-economic strata. Roughly $70 \%$ of our cases originate from Hyderabad and the remaining percentage come from surrounding villages around Hyderabad.

Further these dermatoses may also represent the inadequacies in the primary health care facilities and poor socio-economic status.

The study conducted in our hospital showed similar results compared to study done at the Department of Dermatology and Venereology at JIPMER (Dr. Devinder Mohan Thappa and Team) in 2003 with some minor differences.

Infections and infestations contributed to $52.4 \%$ of total dermatoses as compared to $54.5 \%$ at JIPMER study. Dermatitis and eczema constituted about $29.2 \%$ in our study when compared to $8.6 \%$ (JIPMER).
Papulosquamous dermatoses were about $18.82 \%(1.4 \%$ JIPMER study).

Nutritional dermatoses was about $3.8 \%$ as compared to $2.8 \%$ at JIPMER study.

Urticaria and allergic disorders were about $2.4 \%$, which was similar in JIPMER study.

Drug reactions were about $1.6 \%$ compared to $0.3 \%$ at JIPMER study.

Genetic disorders were $1.5 \%$, whereas it was about $2.5 \%$ at JIPMER study.

Seasonal disorders were about $1.2 \%$ (4.1\% at JIPMER study).

Pigmentary disorders were about $2.5 \%$ and whereas in JIPMER study it was about $5.7 \%$.

Keratinisation disorders constituted $0.4 \%$ and bullous dermatoses constituted about $0.4 \%$ in our study; $4 \%$ of the patients had more than one dermatoses. For Eg: Scabies with secondary infection, tinea capitis with secondary infection, atopic dermatitis with pyoderma.

Scabies was the most common infection in our study and comprised $63.74 \%$ of infections and infestations as compared to JIPMER study where pyodermas was the most common infection (47.13\%). In a study conducted in rural Pakistan, pyoderma was the most common disorder in children ${ }^{10}$ (Porter MJ, Mack RW, Chaudhary MA in Pakistan).

In most other studies, pyodermas of the single most common dermatoses. $(6,7,8,9,10)$

The incidence from scabies varied from $5.1 \%$ to $22.4 \%$ in various studies. $(6,7,8,9,10)$ Two school surveys done in Himachal Pradesh and Pondicherry in India had found pediculosis capitis to the most common dermatological disorder in children.(11)

Incidence of dermatitis and eczema which is about $29.2 \%$ is high when compared to JIPMER study which was about 8.6\%. In Western studies dermatitis and eczema ranged from $18 \%$ to $34 \% .^{(12,13,14)}$ - Another interesting observation is prevalence of atopic dermatitis, which constitutes $15 \%$ of dermatitis and eczema has compared to $0.01 \%$ of total children in the JIPMER study. The study in developed countries report higher incidence ranging from $3.7 \%$ to $28 \% .(15)$

Genetic disorders like ichthyosis, haemangioma, lymphangioma, aplasia cutis were encountered in our study in contrast to studies by Ghosh et $\mathrm{al}^{9}$ and Porter et al, 10 who did not encounter any of these disorders.

There is a higher incidence of papulosquamous dermatoses like psoriasis and lichen planus and drug reactions in our hospital, as our hospital is a tertiary hospital catering to patients in Hyderabad and surrounding villages.

Nutritional dermatoses constituted $3.8 \%$ and papular urticaria constituted to $4.8 \%$ of the study population. Gosh et al(9) observed a lower frequency of $4 \%$ papular urticaria in their study.

Such high frequency of papular urticaria can be explained by the fact that most of the children are from rural and semiurban areas and wear scanty clothing due to poverty and climatic conditions and thus being exposed to insect bites.

Miliaria is another disorders peculiar to hot and humid tropic and was seen in $1.25 \%$ of the children.

The incidents of nutritional dermatoses was seen as 3.8\% of children as most of the children come from rural background and are in poverty. Most of the parents of these 
children were illiterate and were working as agricultural labourers or as domestic help.

\section{CONCLUSION}

Our study brings into light the unique features of tropical dermatology such as high frequency of dermatoses like Infections and Infestations, Eczema and Dermatitis, Environment Associated Disorders like papular urticaria and miliaria.

The occurrence of rare genetic and other dermatoses is remarkable in our institute as our hospital is a tertiary hospital located in Hyderabad City.

We would like to highlight the facts that many of these dermatoses can be controlled by proper sanitation, improving nutrition and environment.

Educating the rural patients and illiterate people about cleanliness, personal hygiene and early detection of skin problem can reduce the incidence of dermatoses attending the hospital.

Institutes likes Colleges, Schools and Hostels should take immediate precaution and treat patients as early as possible. This will enable us to halt a spread of infestations like scabies, which are contagious.

Similarly, parents of children having nutritional dermatoses should be educated about the right nutrition and the importance of balanced diet so that the children will not suffer from any deficiency.

The primary health centre doctors should also play an active role in eradicating these dermatoses, as they are the first people to see many of these skin problems.

\section{REFERENCES}

1. Thappa DM. Common skin problems. India J Pediatr 2002;69(8):701-6.

2. Federman DG, Reid M, Feldman SR, et al. The primary care provider and the care of skin disease. Arch Dermatol 2001;137(1):25-9.

3. Sharma NK, Garg BK, Goel M. Pattern of skin diseases in urban school children. Indian J Dermatol Venereol Leprol 1986;52(6):330-1.
4. Sharma NL, Sharma RC. Prevalence of dermatologic diseases in school children of a high altitude tribal area of Himachal Pradesh. Indian J Dermatol Venereol Leprol 1990;56(5):375-6.

5. Park K. Preventive medicine in obstetrics, pediatrics, and geriatrics. In: Park K, ed. Park's textbook of preventive and social medicine. 17th edn. Jabalpur: Banarsidas Bhanot Publishers 2002:359-411.

6. Negi KS, Kandpal SD, Prasad D. Pattern of skin diseases in children in Garhwal region of Uttar Pradesh. Indian Pediatr 2001;38(1):77-80.

7. Sharma RC, Mendiratta RC. Clinical profile of cutaneous infections and infestations in pediatric age group. Indian J Dermatol 1999;44:174-8.

8. Bhatia V. Extent and pattern of pediatric dermatoses in rural areas of central India. Indian J Dermatol Venereol Leprol 1997;63(1):22-5.

9. Ghosh SK, Saha DK, Roy AK. A clinico aetiological study of dermatoses in pediatric age group. Indian J Dermatol 1995;40:29-31.

10. Porter MJ, Mack RW, Chaudhary MA. Pediatric skin disease in Pakistan. A study of three Punjab villages. Int J Dermatol 1984;23(9):613-6.

11. Kumar V, Garg BR, Baruah MC. Prevalence of dermatological diseases in school children in a semi urban area in Pondicherry. Indian J Dermatol Venereol Leprol 1988;54(6):300-2.

12. Horn R. The pattern of skin diseases in general practice. Dermatol Pract 1986;2:14-19.

13. Johnson MLT, Roberts J. Prevalence of dermatological disease among person 1-74 years of age. No. PHS 791660. Washington DC: US Department of health education, national centre for health statistics 1978.

14. Bowker NC, Cross KW, Fairburn EA, et al. Sociolgoical implications of an epidemiological study of eczema in the city of Birmingham. Br J Dermatol 1976;95(2):137-44.

15. Foley P, Zuo Y, Plunkett A, et al. The frequency of common dermatoses in preschool children in Australia. Atopic dermatitis. Arch Dermatol 2001;137(3):293-300. 